association.) Accordingly, the mean number of associations per figure was computed and used as the index of meaningfulness. The results of this analysis are found in Table 1. From Table 1 it can be seen that no clear trend of relationship of complexity to production $m$ has been obtained. In order to estimate the strength of the relationship, a Pearson correlation was computed, yielding a nonsignificant value of .27 .

\section{DISCUSSION}

The present meaningfulness data, using a close approximation to Noble's technique and the widest range of complexity values yet employed on this topic, has clearly indicated no significant relationship of meaningfulness to complexity. However, variability in meaningfulness has been obtained; the factors that elicit this variability have not been identified here. The lack of relationship of complexity to meaningfulness is particularly interesting in light of the conflicting literature. Two studies have reported lesser meaningfulness for more complex figures (Evans \& Day, 1968; Vanderplas \& Garvin, 1959), but both used short exposure times (15 sec and $3 \mathrm{sec}$, respectively) and both included few levels of complexity ( 3 and 6, respectively, compared to the present 22). Munsinger \& Kessen (1964) reported the opposite result, that is, greater meaningfulness for more complex figures. They used a $10-\mathrm{sec}$ exposure duration and a paired-comparisons technique. However, no actual associative productions were requested of S. Eisenman (1966), using the 4-, 12-, and 24-sided figures from Vanderplas and Garvin, with "unlimited time" for the production of associations, found the middle figure, 12 , to have the highest associative value. On the other hand, the latter authors found that both their 4- and 6-sided figures more often produced high associative values than did the 12-sided one.

The Munsinger and Kessen results are not very readily comparable with the remaining studies because of the important differences in procedure. However, the remaining studies seem primarily differentiated on the temporal variable, that is, the time allowed to produce associations to the stimuli. When relatively brief durations were used (Evans \& Day, Vanderplas \& Garvin), a negative relationship of associative value to complexity was obtained. When a long duration was used (Eisenman), middle values of complexity were most meaningful. However, the latter study indicated that the 12-sided polygon was most meaningful; it should be noted that the simplest polygon employed by Evans and Day had 10 sides and had the highest

associative value. On the other hand, the present 4-, 12-, and 24-sided figures produced the lowest associative value for 12 with the highest for 4 and 24, respectively. Five of the present figures (4, $6,12,16,24)$ replicated the complexity levels reported by Vanderplas and Garvin. However, inspection of the two sets of results indicates that the complexity-association value relationship was not replicated.

The trend of results thus far suggest that the relationship of associative value to complexity may depend on the length of time the $S$ views the figure. It might be hypothesized that, as exposure duration increases from very brief periods, the relationship of complexity to meaningfulness changes from negative to positive. Clearly, research should be undertaken which systematically varies the temporal parameters. It would be advised that such research include a wide range of complexity levels with a number of examples at each level.

On the basis of the present study, however, which has attempted to duplicate procedures widely used in meaningfulness studies with verbal stimuli, it must be concluded that no significant relationship between visual complexity and meaningfulness has been obtained.

\title{
Effects of syntax on running memory span for connected discourse
}

ROBERT J. JARVELLA, ${ }^{1}$ Program in Psycholinguistics, University of Michigan, Ann Arbor, Mich. 48104

Running memory span (RMS) was tested during pauses placed at word boundaries in connected discourse. RMS for the seven words previous to test pauses was superior when all seven fell into the same clause, as opposed to when only the last four words were from the immediate clause. The results gave some support to a hypothesis made about syntactic structure in immediate memory, and their relation to previous findings on speech segmentation in listening was discussed.

Studies on the segmentation of

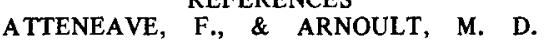
Methodological considerations in the quantitative study of shape and pattern in perception. Psychological Bulletin, 1956, 53, 452-471.

BIRKHOFF, G. D. Aesthetic measure. Cambridge: Harvard University Press, 1933.

DAY, H. I. Evaluations of subjective complexity, pleasingness and interestingness for a series of random polygons varying in complexity. Perception \& Psychophysics, 1967, 2, 281-286.

EISENMAN, R. The association value of random shapes revisited. Psychonomic Science, 1966, 6, 397-398.

EVANS, D. R., \& DAY, H. I. Association value and subjective ratings of interest in visual complexity. Paper presented at American Educational Research Association Annual Meeting, Chicago, February 1968.

MUNSINGER, H., \& KESSEN, W. Uncertainty, structure, and preference. Psychological Monographs, 1964, 78, 1-24.

NOBLE, C. E. An analysis of meaning. Psychological Review, 1952, 59, 421-430.

VANDERPLAS, J. M., \& GARVIN, E. A. The association value of random shapes. Journal of Experimental Psychology, 1959, 57, 147-154.

NOTE

1. The author would like to thank Mrs. Sue Green for assistance in conducting the study. This research was supported in part by the United States Office of Education, Department of Health, Education and Welfare, Center No. C-03/Contract OE 5-10-154. sentences into phrases during speech processing have shown that clicks located acoustically within sentences are displaced toward clause boundaries in listeners' later subjective locations (Fodor \& Bever, 1965 ; Garrett, Bever, \& Fodor, 1966). This finding has been interpreted as evidence that clause structure is actively imposed on the speech signal during listening. The errors made in locating clicks in sentences are considered to be a function of interference with attention to competing sounds during perceptual analysis of the immediate speech stimulus.

In the present study, a similar syntactic effect on the processing of continuous speech was evaluated in a recall task and related to a hypothesis about structural 
representations of speech in immediate memory. It was hypothesized that some internal constituent structure of heard speech would be immediately processed and stored in memory. This syntactically based grouping was furthermore expected to be stored only until the linguistic meaning of the immediate clause was comprehended. Thus represented, this temporary structure would facilitate rehearsal or overt recall of the immediate clause from memory, and at the same time interfere with the constituent structure representation of the previous clause.

The measure employed to test the immediate clause hypothesis was running memory span (Pollack, Johnson, \& Knaff, 1959; Waugh, 1960). RMS was defined in the present experiment as the number of consecutive words that could be recalled from specific (reference) points of interruption in continuous speech. It was predicted that RMS would vary with clause length in words previous to the points of testing. Errors in verbatim recall would occur primarily in previous clause units, across the sentence boundary from immediate clauses.

\section{METHOD}

The Ss were 20 undergraduate students at the University of Michigan. All Ss were tested simultaneously in a single group session.

Two 150-word narrative passages developed by Rosenberg (1966) were adapted to serve as the materials. From each passage, four points approximately 40 words apart were selected for placing test pauses. Of the 56 words occurring in the final seven serial positions before test pauses, 53 had frequencies of 100 or more per million (Thorndike \& Lorge, 1944). Alternate pause points were situated four words after the previous clause boundary (A pauses) and seven words after the previous boundary (B pauses):

A. ... a long table) (while the pretty woman [TEST PAUSE]

B. ....) (a young girl sat on the floor [TEST PAUSE]

The final four.words before $A$ and $B$ pauses were thus all in the immediate clause, but the three words previous to them were in the immediate clause only before B pauses. Before A pauses, the remaining three words were from the previous clause.

The Ss were told they would hear two passages interrupted occasionally by

\section{Table 1}

Percentage Correct Recall for Pause Type and Serial Position

\begin{tabular}{|c|c|c|c|c|c|c|c|}
\hline \multirow{2}{*}{$\begin{array}{c}\text { Type of } \\
\text { Pause }\end{array}$} & \multicolumn{7}{|c|}{ Serial Position from Pause } \\
\hline & 7 & 6 & 5 & 4 & 3 & 2 & 1 \\
\hline A & 71.3 & 75.0 & 88.8 & 97.5 & 97.5 & 96.3 & 98.8 \\
\hline B & 100.0 & 97.5 & 100.0 & 100.0 & 100.0 & 96.3 & 100.0 \\
\hline
\end{tabular}

speech in listening predicts major syntactic constituents to be the relevant units in perception (Fodor \& Bever, 1965). Within the active theory, the differential recall observed for immediate and previous clauses can be interpreted to mean that perceptual segmentation had taken place at the sentence boundary, and that the immediate clause was being processed as a structurally coherent unit when RMS was tested. However, in a recent study comparing reaction time to clicks in sentences with their later subjective location, initial organization and internal representation of heard speech were proposed to constitute separate phases in the perceptual process (Abrams \& Bever, 1969). The RMS task employed in the present study did not distinguish recall based on perceptual analysis completed before test pauses began from recall as a function of analysis carried out after the speech was interrupted. It is possible that some further consolidation of the speech in memory occurred at the beginning of pauses for testing recall.

Inferences drawn from the present results about the psycholinguistic process in listening should be considered to be very tentative. Clearly, the usefulness of RMS as a measure of the influence of syntax on speech perception will be decided by experimental findings for linguistic contexts other than the limited number that were examined. The present results nevertheless demonstrate that running memory span is sensitive to clause structure in heard speech in at least some circumstances. Further research on the role of syntax in speech processing using RMS techniques is warranted.

\section{REFERENCES}

The results obtained suggest that internal clause structure plays an important role in the immediate recall of connected discourse. The facilitation of recall observed for immediate clauses of both lengths tested appears to support the view outlined of some temporary representation of internal constituent structure in memory. The large proportion of errors in recall for words located across the sentence boundary suggests further that, at the time of testing, the representation of the previous clause in memory may have been qualitatively different from that of the immediate one.

The theory of active segmentation of

ABRAMS, K., \& BEVER, T. G. Syntactic structure modifies attention during speech perception and recognition. Quarterly Joumal of Experimental Psychology, 1969, 21, 280-290.

FODOR, J. A., \& BEVER, T. G. The psychological reality of linguistic segments. Journal of Verbal Learning \& Verbal Behavior, $1965,4,414-420$.

GARRETT, M., BEVER, T., \& FODOR, J. The active use of grammar in speech perception. Perception \& Psychophysics, 1966, 1, 30-32. POLLACK, I., JOHNSON, L. B., \& KNAFF, K. Running memory span. Journal of Experimental Psychology, 1959, 57, 137-146. ROSENBERG, S. Associative factors in the recall of connected discourse. Psychonomic Science, 1966, 4, 53-54.

THORNDIKE, E. L., \& LORGE, I. The teacher's word book of 30,000 words. New York: Bureau of Publications, Teachers College, Columbia University, 1944.

WAUGH, N. C. Serial position and the memory-span. American Journal of Psychology, 1960, 73, 68-79.

$$
\text { NOTE }
$$

1. The author is indebted to Dr. Sheldon Rosenberg, Mr. David B. Pisoni, and Mr. Steven J. Herman for their advice on this manuscript. 